\title{
Заключение
}

Результаты внедрения подсистемы показывают, что время автоматизации процессов расчета себестоимости сократилось в 5 раз, время внесения изменений сократилось в 5 раз.

Bсе это позволяет снизить затраты при планировании учебного процесса, упростить технологию планирования, существенно уменьшить трудозатраты на подготовку и обработку данных, снизить количество ошибок и неточностей при расчетно-аналитической работе, согласованности данных в различных подразделениях.

Аналитические возможности системы позволяют администрации вуза осуществлять мониторинг качественных и количественных показателей учебной деятельности.

$$
* * *
$$

1. Бубарева, О.А. Проблемы интеграции множественных источников данных/О.А. Бубарева, Ф.А. Попов// Дистанционное и виртуальное обучение. - 2009. -№ 11(29).-М.: Из-во СГУ, 2009.-С. 85-89.

2. Бубарева, О.А. Решение проблемы интеграции данных при построении интегрированной автоматизированной информационной системы вуза / О.А. Бубарева, Ф.А. Попов, Н.Ю. Ануфриева // Международный журнал экспериментального образования. - 2011.- №5. - С. 90-92.

\section{Омельченко А.Т. \\ Модельный инструментарий поддержки принятия решений при управлении доступом}

ГОУ ВПО «Южно-Российский государственный политехнический университет (НПИ) имени М.И. Платова» (Россия, Новочеркасск)

doi:10.18411/spc-22-11-2017-02

idsp: 000001:spc-22-11-2017-02

В современных условиях хозяйствования деятельность предприятий и фирм значительно усложнена. Причиной тому является как общее кризисное состояние российской экономики, усугубляющееся развитием инфляции, но и ряд специфических факторов, активизирующих различного вида угрозы безопасности предприятия. К числу субъектов, обеспечивающих защиту предприятия от различного вида угроз, относится комплексная система безопасности, неотъемлемой частью которой является система контроля и управления доступом . Система контроля и управления доступом (СКУД) - это комплекс программно-аппаратных и технических, организационных средств безопасности, нацеленных на ограничение и регистрацию входа-выхода на заданную территорию объектов (транспортных средств, людей и др.). Под управлением доступом понимается определение возможности субъекта регулировать возможность доступа к определённому объекту. Концептуальная модель контроля и управления доступом предприятия представлена на рис. 1.

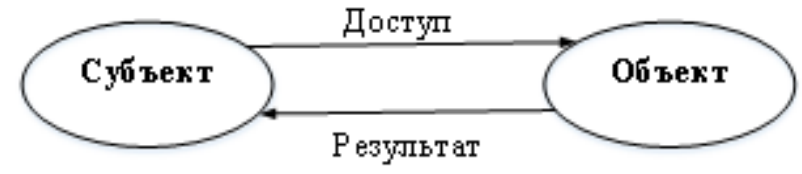

Рис.1. Концептуальная модель контроля и управления доступом предприятия

К создаваемой системе контроля и управления доступом предъявляются определённые требования:

- осуществление контроля за различными перемещениями персонала или посетителей и управление их входом в помещения. 
- организация охраны предприятия от несанкционированного входа, от нанесения вреда имуществу, от всякого рода аварийных ситуаций;

- организация табельного учёта рабочего времени сотрудников.

Принципиальная схема предлагаемой в статье СКУД представлена на рис. 2.

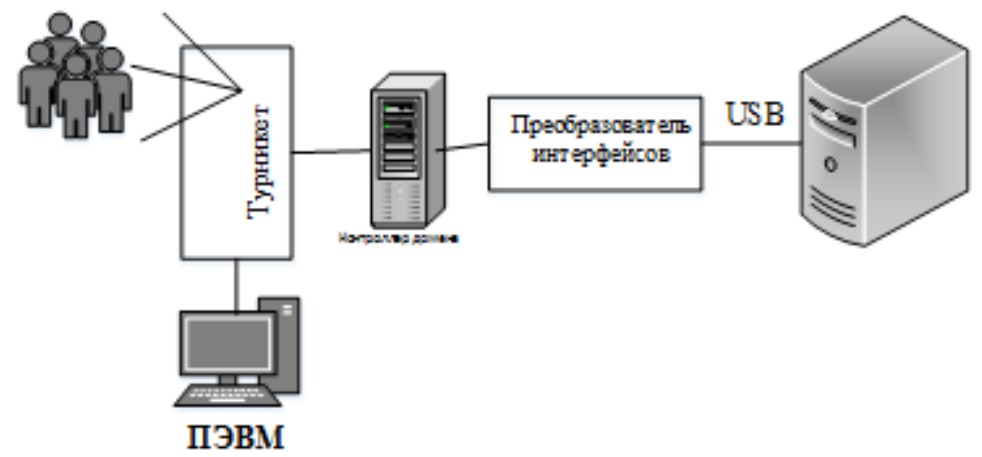

Рис.2. Принципиальная схема СКУД

На рис.2. контроллер разрешает или запрещает проход персонала во время предъявления пропуска или ввода PIN-кода. При этом система может заблокировать или разрешить вход на территорию предприятия. Предполагается выполнение системой основных и дополнительных функций. К числу основных функций относятся:

- регистрация времени прихода и ухода посетителей и сотрудников с целью контроля их присутствия и отсутствия;

- учёт посещаемости объекта клиентами;

- ограничение доступа на заданную территорию;

- идентификация лиц, имеющих доступ на территорию.

Функциональная структура СКУД приведена на рис. 3.

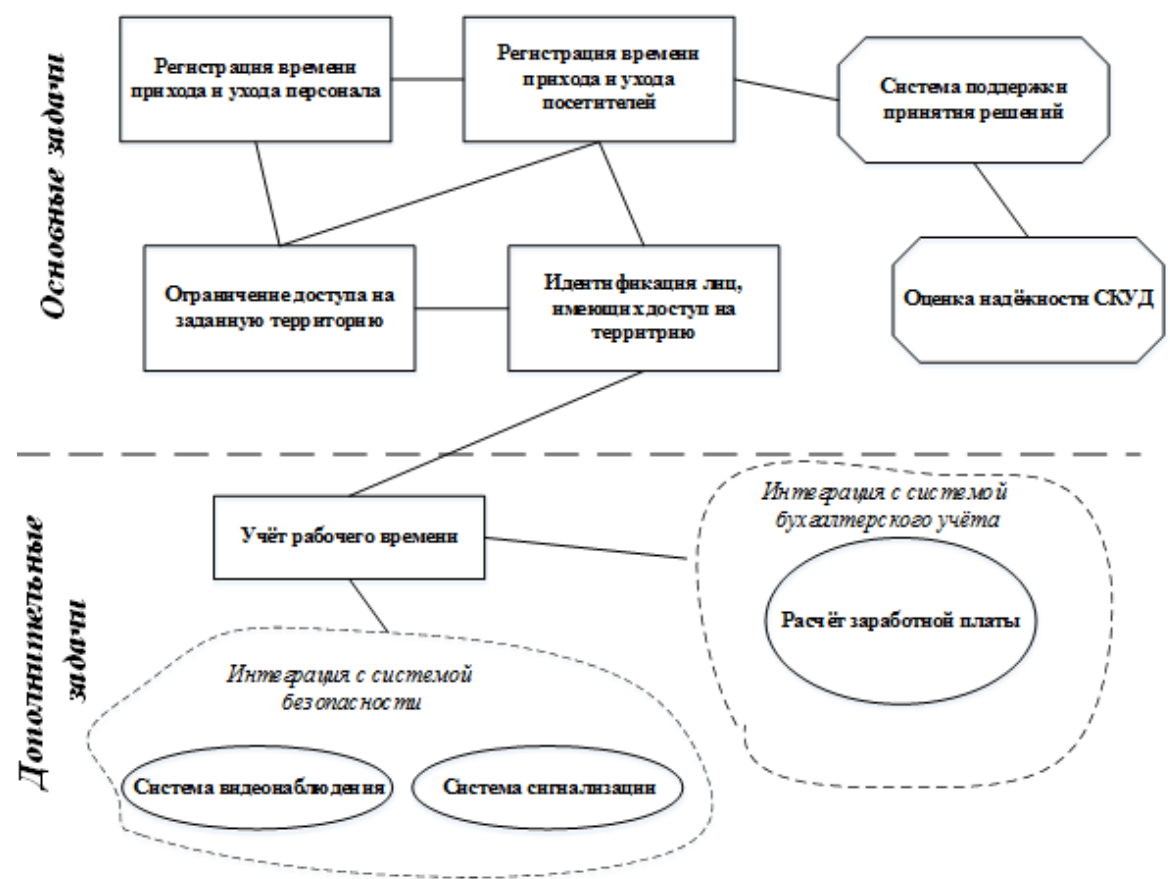

Рис. 3. Функциональная структура системы контроля и управления доступом

Система управления доступом взаимодействует с подсистемами бухгалтерского учёта и системой безопасности. В связи с этим, кроме основных, предполагается выполнение системой СКУД следующих функций:

- учёт рабочего времени;

- учёт заработной платы. 
Выполнение функции «Учёт рабочего времени» осуществляется на основе информации, полученной из подсистемы безопасности.

Одной из главных компонент СКУД является система поддержки принятия решений, построенная на основе применения методов математического моделирования. В современной литературе вопросам создания систем поддержки принятия решений уделено большое внимание. Так, в $[1,2,3,4,5]$ предложены структура и модельный инструментарий, положенные в основу создания и функционирования систем поддержки принятия решений при управлении различными организациями. Автором статьи предполагается создание модельного инструментария для поддержки принятия решений при управлении доступом на основе использования элементов интеллектуализации $[6,7,8,9,10]$. В СКУД включён блок оценки надёжности функционирования СКУД. При этом предложено использовать следующие показатели:

- вероятность безотказной работы

$$
P(t)=1-Q(t)
$$

где $P(t)_{- \text {вероятность безотказной работы системы; }} Q(t)_{- \text {вероятность появления }}$ отказа в течение времени $t$;

- вероятность бесперебойной работы

$$
\widetilde{P}(t)=1-\Omega(t),
$$

где $P(t)_{-}$вероятность отсутствия сбоя; $Q(t)_{-}$вероятность появления сбоя в течение времени $t$;

Таким образом, предложенная система управления контролем доступа на предприятии решает не только задачи безопасности и сохранения материальных ценностей, но и многочисленные вопросы учета рабочего времени, оплаты труда и трудовой дисциплины.

$$
* * *
$$

1. Стрельцова Е.Д. Применение стохастических автоматов для моделирования сложных систем с изменяющимся во времени характером поведения// Известия высших учебных заведений.Электромеханика.-2002.-№3.-С. 76-78

2. Стрельцова Е.Д., Богоягкова И.В., Стрельцов В.С. Модельний інструментарій міжбюджетного регулювання для шахтарських територий// Науковий вісник національного гірничного універсітету.2016.- №4.-С.123-129

3. Стрельцова Е.Д., Федий В.С. Исследование целесообразности поведения и асимптотической оптимальности стохастических автоматов в случайных средах// Известия высших учебных заведений.Электромеханика.-2003.-№3.-С. 67-70

4. Стрельцова Е.Д., Матвеева Л.Г., Богомягкова И.В., Стрельцов В.С. Дискретно-стохастическая модель межбюджетного регулирования// Международный журнал прикладных и фундаментальных исследований.- 2014.-№4.-С. 187-189

5. Стрельцова Е.Д. Математическое обеспечение межбюджетного регулирования в регионе// Прикладная информатика.-2006.-№2(2).-С.114-120

6. Бородин А.И., Стрельцова Е.Д., Ковалёва А.В. Экономико-математическая модель оценки стратегического риска//Вестник Московского авиационного института.-2012.-Т19.-№5.-С.222-232

7. Бородин А.И., Стрельцова Е.Д., Катков Е.В. Оценивание инвестиционной привлекательности инновационных проектов на основе нечёткой логики.-2013.-№4(46).-С.19-25

8. Стрельцова Е.Д., Богомягкова Е.Д., Стрельцов В.С. Управление бюджэетом на основе нечёткой алгебры//Прикладная информатика.-2014.-№4(52).-С. 95-100

9. Стрельцова Е.Д., Дорожко С.В., Бричников Э.М. Программа оценки деформации обмоток силовых трансформаторов по параметрам нормального режима//Известия высших учебных заведений.Электромеханика.-1994.-№56.-С. 91

10. Стрельцова Е.Д., Бородин А.И., Фурсов С. В. Инструментарий стратегического управления промышленным предприятием//Прикладная информатика.-2014.-№2(50).-С. 109-114 